\title{
Brazilian Journal of Medical and Biological Research 1981-2002
}

At the beginning of the 1980's, ten years after the initiation of the successful activities of the new graduate programs for training Master's and Doctoral students, the production of science in Brazil was increasing rapidly and the major scientific societies of the biomedical area decided to create a Journal of international level written entirely in English. José Duarte de Araujo, the Vice-President of the Conselho Nacional de Desenvolvimento Científico e Tecnológico (CNPq), convinced us to adopt and transform an already existing Journal (Revista Brasileira de Pesquisas Médicas e Biológicas, with the English subtitle Brazilian Journal of Medical and Biological Research), created by Michel Jamra, instead of creating a new one, because the journal was already covered in Current Contents. Therefore, in 1981 the Associação Brasileira de Divulgação Científica (ABDC), a federation of Brazilian Scientific Societies (Sociedade Brasileira de Biofísica, Sociedade Brasileira de Bioquímica e Biologia Molecular, Sociedade Brasileira de Farmacologia e Terapêutica Experimental, Sociedade Brasileira de Fisiologia, Sociedade Brasileira de Imunologia, Sociedade Brasileira de Investigação Clínica and Sociedade Brasileira de Neurociências e Comportamento), was created to edit and publish the new Brazilian Journal of Medical and Biological Research. A few years later (1984), the same societies significantly expanded their initiative by creating the Federação de Sociedades de Biologia Experimental (FESBE). The decision was made to maintain ABDC and FESBE as separate entities. However, their interac- tion was facilitated because the Policy Boards of both institutions were composed of representatives of the same societies and one of us, E.M. Krieger, was the first President of FESBE (1985-1991), followed by S.H. Ferreira (1991-1995).

From 1981 to $2002,5,772$ papers were submitted and 3,304 were published (57\%). Over the last eleven years the average number of papers published per year was 200, with $80 \%$ of them originating in Brazil and $20 \%$ from other countries.

The ISI/SCR impact factor in 2001 was 0.769 , the highest during the last 20 years, and the total number of citations in 2001, according to the same source, was 1453 , which is more than any other Journal published in Central and South America. The Journal is edited and published on the Ribeirão Preto campus of USP, where the Faculty of Medicine of the University of São Paulo has provided continuous support. The Journal has been maintained financially by the Ministry of Science and Technology (FINEP and CNPq) and also by the Fundação de Amparo à Pesquisa do Estado de São Paulo (FAPESP).

The Brazilian Journal is now considered to be one of the most successful examples of a scientific Journal of international quality edited in Brazil. Over the last twenty years, the number of $\mathrm{PhD}$ graduates in Brazil increased from approximately 500 to more than 5000 per year. Also, the number of scientific articles from Brazil indexed in international data bases such as ISI increased from approximately 2000 to more than 10,000 per year during the last 20 years. The Brazilian Journal contributed to this impressive growth by publish- 
ing 2 to $4 \%$ of all internationally indexed papers from Brazil during the 1990's.

Perhaps the main contribution of the Journal to the development of Brazilian biomedical research cannot be measured by the number of published papers, but rather by the training of young scientists. By means of the peer review process and with editorial assistance by our staff, authors are being trained to recognize and carry-out quality research and to describe their research clearly in a written document. The policy of the Journal has been and continues to be that if the science is good the Journal will assist the author in preparing the package. The peer review system provides another excellent educational tool for teaching critical analysis. Most of the 5,772 papers submitted to the Journal during these 20 years were reviewed by two or three Brazilian scientists and in most cases all the reviews were circulated to all the referees.

ABDC recently elected Marco Antonio
Zago as President and João Batista Calixto as Secretary to replace Eduardo Moacyr Krieger and Sérgio Henrique Ferreira, respectively. Lewis Joel Greene and Dalva Pizeta were reelected. New blood and new ideas will certainly be of great benefit to the Journal. We do hope that in the near future the number of papers submitted will increase substantially allowing the Journal to publish specific issues for each of its major sections. At the end of our activities as directors of ABDC and editors of the Brazilian Journal of Medical and Biological Research, we want to thank the scientific societies of ABDC for their continuous support and confidence in our activities. We also want to express our warm wishes for the continued success of the Journal to Marco A. Zago, João Batista Calixto, Lewis J. Greene and Dalva Pizeta.

Eduardo Moacyr Krieger Sérgio Henrique Ferreira 